\title{
Suppression of Powdery Mildew (Podosphaera pannosa) in Greenhouse Roses by Brief Exposure to Supplemental UV-B radiation
}

A. Suthaparan, Department of Plant \& Environmental Sciences, Norwegian University of Life Sciences, 1432 Ås, Norway; A. Stensvand, Norwegian Institute for Agricultural and Environmental Research (Bioforsk), Høgskoleveien 7, 1432 Ås, Norway; K. A. Solhaug, Department of Ecology and Natural Resource Management, Norwegian University of Life Sciences; S. Torre and L. M. Mortensen, Department of Plant \& Environmental Sciences, Norwegian University of Life Sciences; D. M. Gadoury and R. C. Seem, Department of Plant Pathology and Plant-Microbe Biology, Cornell University, New York State Agricultural Experiment Station, Geneva, NY 14456 USA; and H. R. Gislerød, Department of Plant \& Environmental Sciences, Norwegian University of Life Sciences

\begin{abstract}
Suthaparan, A., Stensvand, A., Solhaug, K. A., Torre, S., Mortensen, L. M., Gadoury, D. M., Seem, R. C., and Gislerød, H. R. 2012. Suppression of powdery mildew (Podosphaera pannosa) in greenhouse roses by brief exposure to supplemental UV-B radiation. Plant Dis. 96:1653-1660.

Ultraviolet (UV)-B (280 to $315 \mathrm{~nm}$ ) irradiance from 0.1 to $1.2 \mathrm{~W} \mathrm{~m}^{-2}$ and exposure times from 2 min to $2 \mathrm{~h}$ significantly suppressed powdery mildew (Podosphaera pannosa) in pot rose (Rosa $\times$ hybrida 'Toril') via reduced spore germination, infection efficiency, disease severity, and sporulation of surviving colonies. Brief daily exposure to UV-B suppressed disease severity by more than $90 \%$ compared with unexposed controls, and severity was held at low levels as long as daily brief exposures continued. Selective removal of wavelengths below $290 \mathrm{~nm}$ from the UV lamp sources by cellulose diacetate filters resulted in significant reduction of treatment efficacy. Exposure of plants

to $2 \mathrm{~h}$ of UV-B during night for 1 week followed by inoculation with $P$. pannosa did not affect subsequent pathogen development, indicating that the treatment effect was directly upon the exposed pathogen and not operated through the host. Following 20 to 30 days of exposure, chlorophyll and flavonoid content was slightly higher in plants exposed to the highest UV-B levels. Brief daily exposure to UV-B for $5 \mathrm{~min}$ at $1.2 \mathrm{~W} \mathrm{~m}^{-2}$ or $1 \mathrm{~h}$ at $0.1 \mathrm{~W} \mathrm{~m}^{-2}$ substantially reduced mildew severity without significant phytotoxicity, and may represent a useful nonchemical option for suppression of powdery mildew in greenhouse roses and, possibly, other crops.
\end{abstract}

Powdery mildew caused by Podosphaera pannosa is the most problematic fungal disease in greenhouse-grown roses (Rosa $\times$ hybrida). Climatic conditions in the greenhouse are ideal for reproduction and spread of powdery mildew. The high frequency of fungicide applications that is required to suppress powdery mildew often results in rapid selection for fungicide resistance (7). Manipulation of environmental conditions, including day length (32) and spectral quality of the light $(33,35)$, may provide an alternative strategy to reduce powdery mildew in greenhouse crops.

The electromagnetic spectrum of ultraviolet (UV) is subdivided into vacuum UV ( $<200 \mathrm{~nm}$ ), UV-C (200 to $280 \mathrm{~nm}$ ), UV-B (280 to $315 \mathrm{~nm}$ ), and UV-A (315 to $400 \mathrm{~nm}$ ) (3). UV-C is strongly biocidal due to its direct effect upon DNA (3). UV-B has been investigated for possible negative effects on higher plants, and such effects are strongly dependent on plant species and UV-B dose (intensity $\times$ duration) (4,6). Most of the biological responses affected by electromagnetic radiation within the UV range are not linearly related to increasing intensity at each wavelength $(9,34)$, and different biological spectral weighting functions have been developed for calculating biologically effective UV-B (UV-B $B_{B E}$ ) for various plant responses $(9,16)$.

Several studies have focused on the effect of UV-B radiation on microorganisms under laboratory conditions (18). Differential doses of UV-C have been investigated for suppression of grapevine powdery mildew (Erysiphe necator) but phytotoxicity to the host occurred at doses near those required for optimal disease suppression (10). A limited number of studies have focused on finding a practical use of UV-B to control plant diseases. Increased UV-B

Corresponding author: A. Suthaparan,

E-mail: aruppillai.suthaparan@umb.no

Accepted for publication 25 May 2012.

http://dx.doi.org/10.1094/PDIS-01-12-0094-RE

(C) 2012 The American Phytopathological Society dose was reported to be an important component in the reduced severity of grapevine powdery mildew when plant canopies were manipulated to increase light penetration (1). However, contradictory effects have also been reported wherein severity of powdery mildew increased (28) or decreased (36) following exposure to UV-B. Calculated exposures in the foregoing studies involved either the UV-B portion of natural solar radiation or supplemental UV-B radiation that duplicated the UV-B spectrum of natural solar radiation $(28,36)$. It remains unclear precisely what portion of the UV-B waveband contributed to the reported effects; whether effects on detached tissues are relevant to whole plant systems, are directly upon the pathogen, or are mediated through host responses; or whether treatments are injurious to whole plants.

We have completed a series of experiments in which measured doses of known wavelengths within the UV-B radiation band were applied to pot roses (Rosa $\times$ hybrida 'Toril') before and after inoculation with the rose powdery mildew pathogen $P$. pannosa in which we were able to resolve much of the uncertainty regarding how UV-B radiation affects severity of powdery mildew within this system. A preliminary report of this work has been published (31).

\section{Materials and Methods}

Plant production. Pot rose Toril plants were propagated and grown in greenhouse compartments. Transplants were planted into 12-cm-diameter plastic pots containing a standard limed fertilized peat medium (VEKSTTORV; Ullensaker Almenning). Plants were maintained at a minimum air temperature of $20^{\circ} \mathrm{C}$ and set air relative humidity $(\mathrm{RH})$ of $70 \%$. Plants were irrigated with a complete nutrient solution (Superba Rød; Yara Norge AS) when needed. Supplemental lighting was provided by high-pressure sodium (HPS) lamps (Lucalox LU400/XO/T/40; GE Lighting) to maintain a day length of $18 \mathrm{~h}$ (from 0400 to 2200 WET) with minimum photosynthetic photon flux (PPF) (400 to $700 \mathrm{~nm}$ ) of $200 \pm 20$ $\mu \mathrm{mol} \mathrm{m} \mathrm{m}^{-2} \mathrm{~s}^{-1}$ at plant height (Fig. 1A). Lamps were turned on when natural solar irradiance declined below $200 \mathrm{~W} \mathrm{~m}^{-2}$. Plants were pruned once, to promote formation of uniform and vigorous shoots. 
Inoculum preparation. $P$. pannosa was isolated from diseased leaves of greenhouse-grown roses at the Norwegian University of Life Sciences. A clonal isolate was produced through sequential transfer of single conidial chains to petri dishes containing detached, disease-free rose leaves on water agar, as described previously (32) and, once obtained, was maintained in isolation on leaves of the above system.

Disease-free Toril roses were spray inoculated by conidial suspensions prepared from mildew colonies developed on leaf tissue in petri dishes as mentioned above. Mildewed leaves with newly sporulating colonies were shaken in distilled water containing Tween 20 surfactant (Sigma-Aldrich Chemie $\mathrm{GmbH}$ ) at $20 \mu \mathrm{l}$ liter $^{-1}$ and adjusted to a concentration of 2.5 to $4.0 \times 10^{4}$ conidia/ml. Suspensions of conidia were applied to plants using a hand-held spray atomizer at the rate of $10 \mathrm{ml} /$ plant. Inoculated plants were kept in an isolated growth chamber with diurnal lighting of $14 \mathrm{~h}$ supplied by mercury lamps (Powerstar HQI-BT 400 W/D day light; OSRAM GmbH) (Fig. 1A) at a PPF of $130 \pm 10$ $\mu \mathrm{mol} \mathrm{m} \mathrm{m}^{-2}, 20 \pm 0.5^{\circ} \mathrm{C}$, and $75 \pm 2 \% \mathrm{RH}$. The pathogen inoculum was renewed weekly by replacing the old plants with newly inoculated plants throughout the experiment.

Pre- and post-inoculation exposure to UV-B during night. In total, 32 plants, each having one developing shoot with two fully unfolded leaves, were divided into two groups (16 plants in each). Each group of plants was exposed to one of the following two light treatments daily for 7 days: (i) $18 \mathrm{~h}$ of white light (i.e., solar radiation supplemented with HPS lamps as previously described) followed by $6 \mathrm{~h}$ of darkness or (ii) $18 \mathrm{~h}$ of white light followed by $2 \mathrm{~h}$
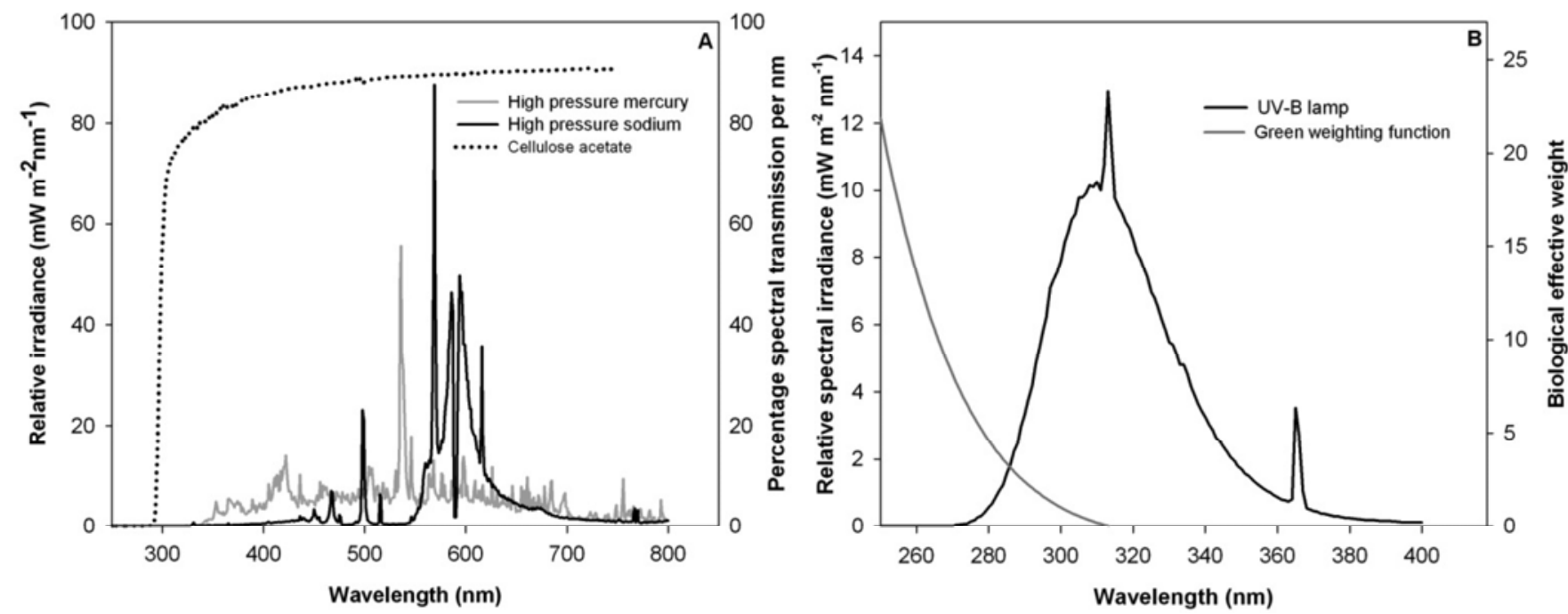

Fig. 1. Spectral distribution measured at 1-nm wavelength intervals of $\mathbf{A}$, the radiation sources of high pressure sodium (HPS), mercury lamps and transmission properties of cellulose diacetate B, UV-B fluorescent tubes compared with the Green weighting function (16) normalized to 1 at $300 \mathrm{~nm}$.

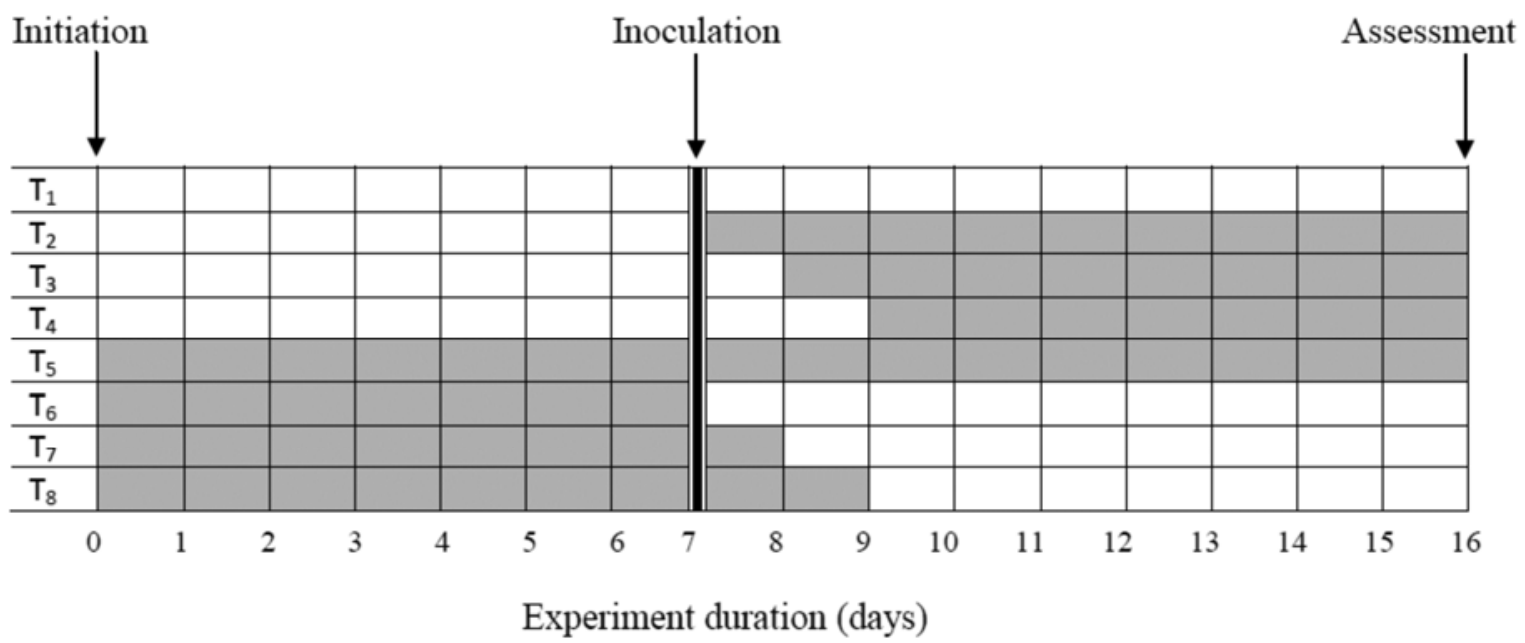

\author{
$18 \mathrm{~h} \mathrm{~W} \mathrm{~L}+6 \mathrm{~h} \mathrm{D}$ \\ $18 \mathrm{~h} \mathrm{~W} \mathrm{~L}+2 \mathrm{~h} \mathrm{D}+2 \mathrm{~h} \mathrm{UV}-\mathrm{B}+2 \mathrm{~h} \mathrm{D}$
}

Fig. 2. Schematic illustration for the time series activities during the experiment with pre- and post-inoculation exposure to UV-B. Roses grown under $18 \mathrm{~h}$ of white light (WL) were kept in the same lighting conditions throughout the experiment $\left(T_{1}\right)$ or moved to lighting conditions of $18 \mathrm{~h}$ of WL $+2 \mathrm{~h}$ of darkness (D) $+2 \mathrm{~h}$ of UV-B $+2 \mathrm{~h}$ of $D$ immediately after inoculation $\left(T_{2}\right), 24 \mathrm{~h}$ after inoculation $\left(T_{3}\right)$ or $48 \mathrm{~h}$ after inoculation $\left(T_{4}\right)$. Roses grown under lighting conditions of $18 \mathrm{~h}$ of WL $+2 \mathrm{~h}$ of $\mathrm{D}+2 \mathrm{~h}$ of $\mathrm{UV}$ - $\mathrm{B}+2 \mathrm{~h}$ of $\mathrm{D}$ were kept in the same conditions throughout the experiment $\left(\mathrm{T}_{5}\right)$ or moved to $18 \mathrm{~h}$ of WL immediately after inoculation $\left(\mathrm{T}_{6}\right), 24 \mathrm{~h}$ after inoculation $\left(\mathrm{T}_{7}\right)$, or $48 \mathrm{~h}$ after inoculation $\left(\mathrm{T}_{8}\right)$. 
of darkness, $2 \mathrm{~h}$ of UV-B, and then $2 \mathrm{~h}$ of darkness. Absolute UV-B irradiance of $0.184 \pm 0.01 \mathrm{~W} \mathrm{~m}^{-2}\left(\mathrm{UV}-\mathrm{B}_{\mathrm{BE}}\right.$ of $\left.0.288 \mathrm{~W} \mathrm{~m}^{-2}\right)$ at plant height was supplied by $120-\mathrm{cm}$ UV-B tubes (model UVB313EL; Q-PANEL Lab Products) (Fig. 1B). All plants were subsequently incubated under the air temperature and $\mathrm{RH}$ conditions described above for plant production.

After 7 days of exposure to light treatments (i) and (ii), plant development had advanced to five fully unfolded leaves. The 16 plants exposed to each light treatment were then arbitrarily divided into four subgroups (four plants in each subgroup). All plants were then inoculated by spraying with $10 \mathrm{ml}$ of conidial suspension prepared as described above. Subgroups of four inoculated plants were then exposed to lighting treatments (i) or (ii) above for an additional 9 days as follows: plants initially in (i) or (ii) remained in (i) or (ii), were moved from (i) to (ii), or moved from (ii) to (i) at $0 \mathrm{~h}$ after inoculation, $24 \mathrm{~h}$ after inoculation, or $48 \mathrm{~h}$ after inoculation (Fig. 2).

Nine days after inoculation, the percentage of the upper (adaxial) leaf surface covered by mildew colonies was assessed by observing five inoculated leaves on each plant. After assessment, mildewed leaves were individually agitated in 50-ml centrifuge tubes containing $10 \mathrm{ml}$ of distilled water and Tween 20 at the concentration of $20 \mu \mathrm{liter}{ }^{-1}$ of water. The number of conidia per milliliter of suspension was calculated in two aliquots of suspension microscopically using a hemocytometer (HYCOR; Hycor Biomedical, Inc.). The experiment was conducted twice. Each plant was treated as a replicate in summarizing and analyzing responses.

Optimum intensity and duration of UV-B. Eight roses, each having a single shoot of approximately 2 to $4 \mathrm{~cm}$ with no unfolded leaves, were exposed daily to each of the following treatments until plants developed five fully unfolded leaves: (i) $18 \mathrm{~h}$ of white light followed by $6 \mathrm{~h}$ of darkness as control, or $18 \mathrm{~h}$ of white light followed by $2 \mathrm{~h}$ of darkness followed by either (ii) $1 \mathrm{~h}$ of UV-B at 0.1 $\mathrm{W} \mathrm{m}{ }^{-2}$, (iii) $1 \mathrm{~h}$ of UV-B at $0.2 \mathrm{~W} \mathrm{~m}^{-2}$, (iv) $2 \mathrm{~h}$ of UV-B at $0.1 \mathrm{~W}$ $\mathrm{m}^{-2}$, or (v) $2 \mathrm{~h}$ of UV-B at $0.2 \mathrm{~W} \mathrm{~m}^{-2}$ (Fig. 3). UV-B irradiance of either $0.1 \pm 0.01\left(U V-B_{\mathrm{BE}}=0.158\right)$ or $0.2 \pm 0.01\left(U V-B_{\mathrm{BE}}=0.310\right)$ $\mathrm{W} \mathrm{m}{ }^{-2}$ was supplied by the same type of UV-B lamps as described above.

When the above plants reached the stage of five fully unfolded leaves, they were inoculated with powdery mildew as described above. The experiment was conducted twice, using an inoculum concentration of $3.2 \times 10^{4}$ and $1.7 \times 10^{4}$ conidia/ml, respectively. Nine days after inoculation, the five inoculated leaves on each plant were assessed for percentage of leaf area diseased and spore production, as described previously.

Effect of UV-B on conidial germination and infection efficiency. Twenty rose plants with single shoots were grown under the plant production greenhouse conditions described above until they bore five fully unfolded leaves. The shoot tips were pinched to suppress further shoot extension, and the plants were inoculated with a spore suspension containing $3.5 \times 10^{4}$ conidia $/ \mathrm{ml}$ as described above. Groups of four plants were then exposed to treatments (i) to (v) described above (Fig. 3).

At 2 and 3 days after inoculation, one leaflet from the uppermost leaf of each plant was detached and assessed for conidial germination and infection efficiency, respectively. For microscopy, leaflets were submerged in 3:1 ( $\mathrm{vol} / \mathrm{vol})$ ethanol and glacial acetic acid for $6 \mathrm{~h}$ to clear the tissue, then stained with $5 \%$ acid fuchsin in $50 \%$ lactic acid, mounted on glass slides, and scanned under a light microscope at $\times 400$. Germination of conidia was calculated for 50 individual conidia of each leaflet. Conidia were considered germinated when the germ tube length was equal to or longer than the conidial width, and germ tubes with secondary branching were considered to represent successful establishment of the pathogen for the purpose of computing infection efficiency.

Effects of brief night time exposure to high intensity UV-B. Single-shoot roses were grown under plant production greenhouse conditions. At the stage of five fully unfolded leaves on each shoot, 20 plants were inoculated with a powdery mildew spore suspension with concentration of $4.0 \times 10^{4}$ conidia/ml, as described previously. Immediately after inoculation, plants were exposed daily to either $18 \mathrm{~h}$ of white light as described above, with or without UV-B as night interruption for 9 days. For night interruption, UV-B irradiance of $1.1 \mathrm{~W} \mathrm{~m}^{-2}$ for either 2 or $5 \mathrm{~min}$ was applied daily at midnight ( $2 \mathrm{~h}$ into the dark period) during the experimental period. Percent diseased leaf area was assessed 9 days after inoculation.

Effective part of the UV-B spectrum. To assess the effect of the lower wavelength part of UV-B on powdery mildew, an experiment was set up using a $0.15-\mathrm{mm}$ clear cellulose diacetate foil (Jurgen Rachow GmbH) that blocks UV-B wavelengths below 290 $\mathrm{nm}$ (Fig. 1A). Twenty-four plants (single shoot), each having five unfolded leaves grown under plant production greenhouse conditions, were divided into four groups of six plants. Each plant was inoculated as described above. Concentration of the spores in the suspension was $3.5 \times 10^{4} \mathrm{conidia} / \mathrm{ml}$. Plants were exposed to the following treatments for 9 days from the time of inoculation. Treatments were either (i) $18 \mathrm{~h}$ of white light as described above, with or without filtration by cellulose diacetate, or (ii) $18 \mathrm{~h}$ of white light followed by $2 \mathrm{~h}$ of darkness, followed by $1 \mathrm{~h}$ of UV-B with or without filtration by cellulose diacetate, followed by $3 \mathrm{~h}$ of darkness. The intensity of UV-B $\mathrm{B}_{\mathrm{BE}}$ with and without cellulose diacetate at plant height level was $0.15 \pm 0.01 \mathrm{~W} \mathrm{~m}^{-2}$ (Table 1). At the end of the experiment ( 9 days after inoculation), the inoculated five leaves of each plant were assessed for disease severity and sporulation as described above.

Effect of UV-B on plant growth. In total, 80 roses, each with 2 to $4 \mathrm{~cm}$ of single growing shoots with no leaves, were exposed to each of the five lighting treatments (16 plants/treatment) (Fig. 3).

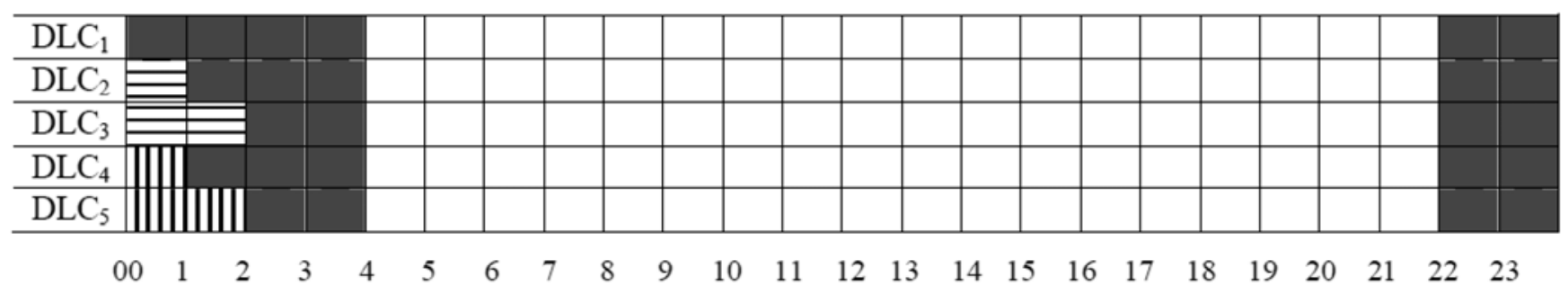

Time of day (hours)

Fig. 3. Schematic illustration of daily light cycle (DLC) for different treatments in greenhouse experiments to determine the optimum UV-B intensity and duration. Plants were exposed to $18 \mathrm{~h}$ of white light (WL) followed by $6 \mathrm{~h}$ of darkness (D), or the dark period was interrupted by UV-B radiation for either 1 or $2 \mathrm{~h}$, with intensities of either 0.1 or 0.2 $W \mathrm{~m}^{-2}$. 
Plants in each treatment were further arranged into four groups, each with four plants. Growing shoot tips of the plants in group one were pinched off when four leaves were unfolded to control plant growth. Relative chlorophyll content and chlorophyll fluorescence (photosystem II efficiency) were measured on the upper two leaves in each plant at 10,20, and 30 days after start of the treatment. Relative chlorophyll content was estimated with a hand-held chlorophyll content meter (model-CL01; Hansatech Instruments). Maximal photosystem II efficiency (variable fluorescence $\left[\mathrm{F}_{\mathrm{v}}\right] /$ maximum fluorescence $\left[\mathrm{F}_{\mathrm{m}}\right]$ ) was measured with a portable chlorophyll fluorometer (Plant Efficiency Analyzer, Hansatech Instruments) using excitation light of about 1,500 $\mu \mathrm{mol}$ photons $\mathrm{m}^{-2} \mathrm{~s}^{-1}$ after 15 min of dark adaptation.

Plants in group two and three (four plants in each group, eight plants in each treatment) were assessed for plant height and number of unfolded leaves 5, 10, 15, and 20 days after exposure. In addition, number of visible flower buds was also counted 20 days after exposure. Height of the shoot was defined as the distance from the base of the shoot to the node of the fully unfolded uppermost leaf.

Plants in group three in each treatment (four plants per treatment) were also assessed for relative anthocyanin and flavonol content by fluorescence excitation ratio method (5) at the same time interval as for plant height assessment with a hand-held Multiplex 3 multi-excitation wavelength chlorophyll fluorometer (Force-A). Three repeated measurements were carried out for each plant canopy. The measurements were standardized with the blue foil from the manufacturer. With this standardization, the amount of anthocyanins and flavonols was estimated as the green and UVA light absorbance relative to the supplied blue standard.

Leaf area and fresh and dry weight of unfolded leaves were assessed at 10, 20, and 30 days after treatment, respectively, using four plants per treatment on each assessment date. An LI-3100 area meter (Li-Cor Inc.) was used for leaf area measurements. The fresh and dry weights for the remaining above-soil plant parts (stem + petiole + tip) were also recorded by electronic balance. For dry weight assessment, samples were kept at $70^{\circ} \mathrm{C}$ for 10 days.

Recording of environmental conditions. Light intensity supplied by HPS and mercury lamps at plant height was recorded with a digital quantum meter (model QMSW-SS; Apogee Instruments Inc.) containing a quantum sensor. Spectral quality of the HPS, mercury, and UV-B lamps was recorded with an Optronic spectroradiometer (model 756; Optronic Laboratories). The intensity of the UV-B irradiance was measured with a SKYE SKU430 sensor (Skye instruments Ltd.) calibrated for the UV-B sources with an Optronic spectroradiometer (model 756; Optronic Laboratories). UV-B $B_{B E}$ was calculated from these readings based on generalized plant damage action spectrum function normalized to $300 \mathrm{~nm}$ (16). The intensity of UV-A, with and without cellulose diacetate, was measured by a SKYE SKU426/SS2 38582 sensor (Skye Instruments Ltd.). Spectral transmission properties of the cellulose diacetate film were measured by spectrophotometer (model Shimadzu UV-2100 PC; Shimadzu Corporation). A Priva greenhouse computer (Priva) recorded air temperature and RH at 5-min intervals.

Data analysis. Minitab (version 16) was used to conduct analysis of variance (GLM procedure). Factors, experimental repeat, replicate, and interaction between treatment and experimental repeat were included in the model. Comparisons of means were performed with Tukey's pairwise comparison test at $P=0.05$. Disease

Table 1. Irradiances ( $\mathrm{W} \mathrm{m}^{-2}$ ) of UV-A, UV-B, and the biologically effective UV-B $\left(U V-B_{\mathrm{BE}}\right)$ that reached the plant surface during the experiment with cellulose diacetate ${ }^{\mathrm{Z}}$

\begin{tabular}{lccc}
\hline Treatment & UV-A & UV-B & UV-B $_{\text {BE }}$ \\
\hline White light + cellulose diacetate & 0.08 & 0.00 & 0.00 \\
UV-B + cellulose diacetate & 0.43 & 0.15 & 0.15 \\
UV-B - cellulose diacetate & 0.17 & 0.10 & 0.15 \\
\hline
\end{tabular}

${ }^{\mathrm{z}} \mathrm{UV}_{\mathrm{BE}}$ was calculated according to Green weighting function (16) normalized to 1 at $300 \mathrm{~nm}$. severity and sporulation were analyzed for one factor (light treatment) as single-factor experiments. Student's two-sample $t$ tests were performed for experiments of brief night-time exposure to high-intensity UV-B radiation. Two-factor (light treatment and days of exposure) factorial models were used for the analysis of plant growth. Normality of the data was examined by normal probability plot analysis, and data were transformed if necessary.

\section{Results}

Pre- and post-inoculation exposure to UV-B during night. Exposure of plants to UV-B prior to inoculation followed by daylight-balanced lighting after inoculation (Fig. 2, $\mathrm{T}_{6}$ ) did not reduce severity of powdery mildew compared with inoculated control plants that were not exposed to UV-B (Fig. 4). Plants exposed to UV-B from time of inoculation or from 1 or 2 days after inoculation (Fig. 2; $\mathrm{T}_{2}, \mathrm{~T}_{3}$, and $\mathrm{T}_{4}$ ) developed no or very little powdery mildew compared with the non-exposed control plants $(P<$ 0.0001; Fig. 4 A). When plants were exposed to UV-B during the night period of only during the first or second day after inoculation, disease severity was reduced to 9.5 and $6.5 \%$, respectively, compared with the $34.2 \%$ severity observed on unexposed control plants. All post-inoculation exposure of plants to UV-B significantly reduced the number of spores produced compared with unexposed control plants $(P<0.0001$; Fig. 4 B).

Optimum intensity and duration of UV-B. Disease severity was reduced from $19 \%$ in the non UV-B exposed control to $0.73 \%$

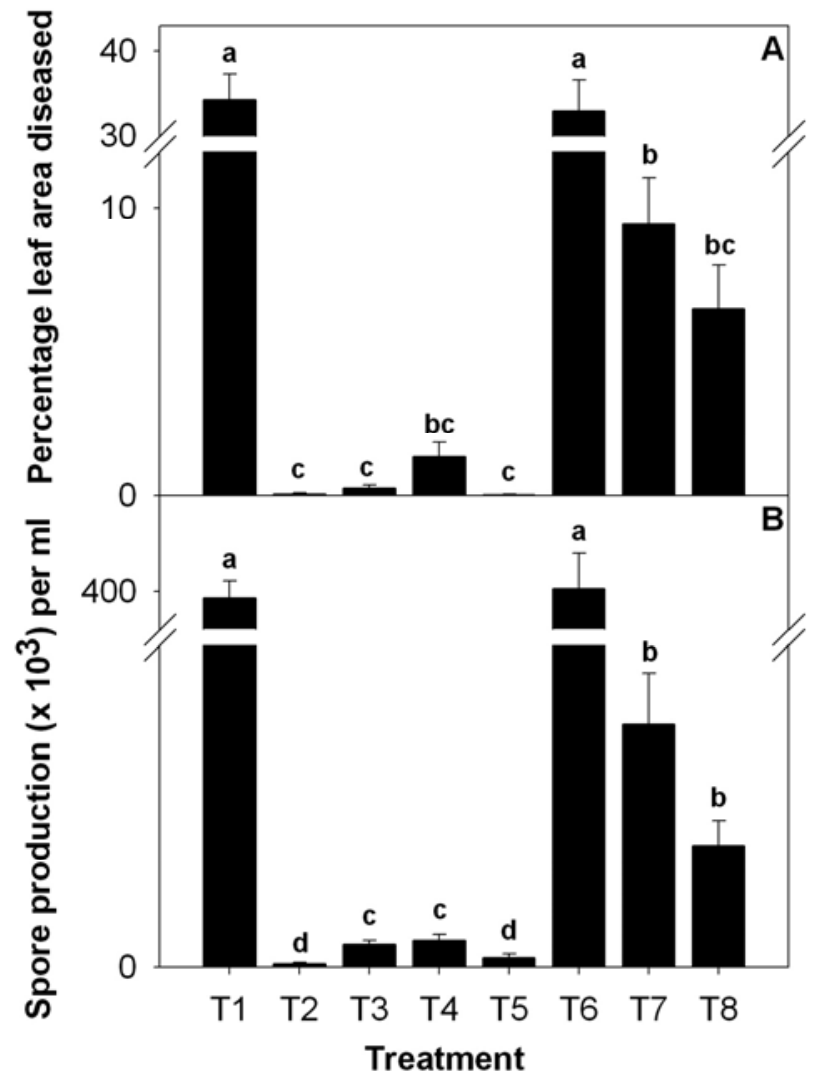

Fig. 4. Effect of UV-B treatments on A, disease severity and B, spore formation 9 days after inoculation with Podosphaera pannosa on pot rose (Rosa $\times$ hybrida) 'Toril'. Roses grown under daily light cycles of $18 \mathrm{~h}$ of white light (WL) were kept in the same lighting conditions throughout the experiment $\left(T_{1}\right)$ or moved to lighting conditions of $18 \mathrm{~h}$ of WL $+2 \mathrm{~h}$ of darkness (D) $+2 \mathrm{~h}$ of UV-B immediately after inoculation $\left(\mathrm{T}_{2}\right), 24 \mathrm{~h}$ after inoculation $\left(\mathrm{T}_{3}\right)$, or $48 \mathrm{~h}$ after inoculation $\left(\mathrm{T}_{4}\right)$. Roses grown under daily light cycles of $18 \mathrm{~h}$ of WL $+2 \mathrm{~h}$ of $\mathrm{D}+2 \mathrm{~h}$ of UV-B were kept in the same conditions throughout the experimental period $\left(\mathrm{T}_{5}\right)$ or moved to $18 \mathrm{~h}$ of WL immediately after inoculation $\left(\mathrm{T}_{6}\right), 24 \mathrm{~h}$ after inoculation $\left(\mathrm{T}_{7}\right)$, or $48 \mathrm{~h}$ after inoculation $\left(T_{8}\right)$. Data for spore production were log transformed $(1+$ number of spores) before analysis, and back-transformed data are presented here. Error bars indicate the standard error of the mean for two repeated experiments, and significant difference between treatments is denoted by different letters $(P=0.05)$. 
if exposed to UV-B at $0.1 \mathrm{~W} \mathrm{~m}^{-2}$ for $1 \mathrm{~h}$, and the severity was further reduced to nil if exposed to UV-B at $0.2 \mathrm{~W} \mathrm{~m}^{-2}$ for $2 \mathrm{~h}(P=$ 0.0001; Fig. 5A). All UV-B treatments significantly reduced severity and conidial production $(P=0.0001$; Fig. 5). All UV-B treatments significantly $(P<0.0001)$ reduced conidial germination from $33.3 \%$ in the untreated controls to 3.5 to $11.3 \%$ across the different UV-B treatments (Table 2). Infection efficiency was significantly $(P<0.0001)$ reduced to 0.2 to $2 \%$ across the various UV-B treatments versus $13.5 \%$ observed on leaves of the untreated controls (Table 2). A UV-B intensity of $0.2 \mathrm{~W} \mathrm{~m}^{-2}$ was slightly more effective than $0.1 \mathrm{~W} \mathrm{~m}^{-2}$ but the exposure times of 1 or $2 \mathrm{~h}$ did not significantly affect germinability or infection efficiency (Table 2). Increasing UV-B intensity to $1.2 \mathrm{~W} \mathrm{~m}^{-2}$ with an exposure time of 2 or 5 min reduced disease severity by a factor of 2.6 $(P=0.001)$ and $51(P=0.0001)$, respectively, compared with unexposed controls (Fig. 6).

Effect of short-wavelength UV-B. Nonfiltered UV-B, including radiation below $290 \mathrm{~nm}$, significantly $(P=0.00001)$ reduced disease severity to $2 \%$, compared with approximately $15 \%$ in the unexposed control (Fig. 7A), with a similar reduction in conidial production (Fig. 7B). When a cellulose diacetate filter was used to remove all UV-B wavelengths below $290 \mathrm{~nm}$, there was no suppressive effect on powdery mildew (Fig. 7).

Effect of UV-B on plant chlorophyll, flavonol, anthocyanin, and photosystem II efficiency. Compared with $18 \mathrm{~h}$ of daylightbalanced light, the relative content of chlorophyll increased significantly with all combinations of UV-B treatments, except $1 \mathrm{~h}$ with UV-B at $0.1 \mathrm{~W} \mathrm{~m}^{-2}(P=0.0009$; Table 3$)$. There were no significant differences among the other three UV-B treatments (Table 3 ).

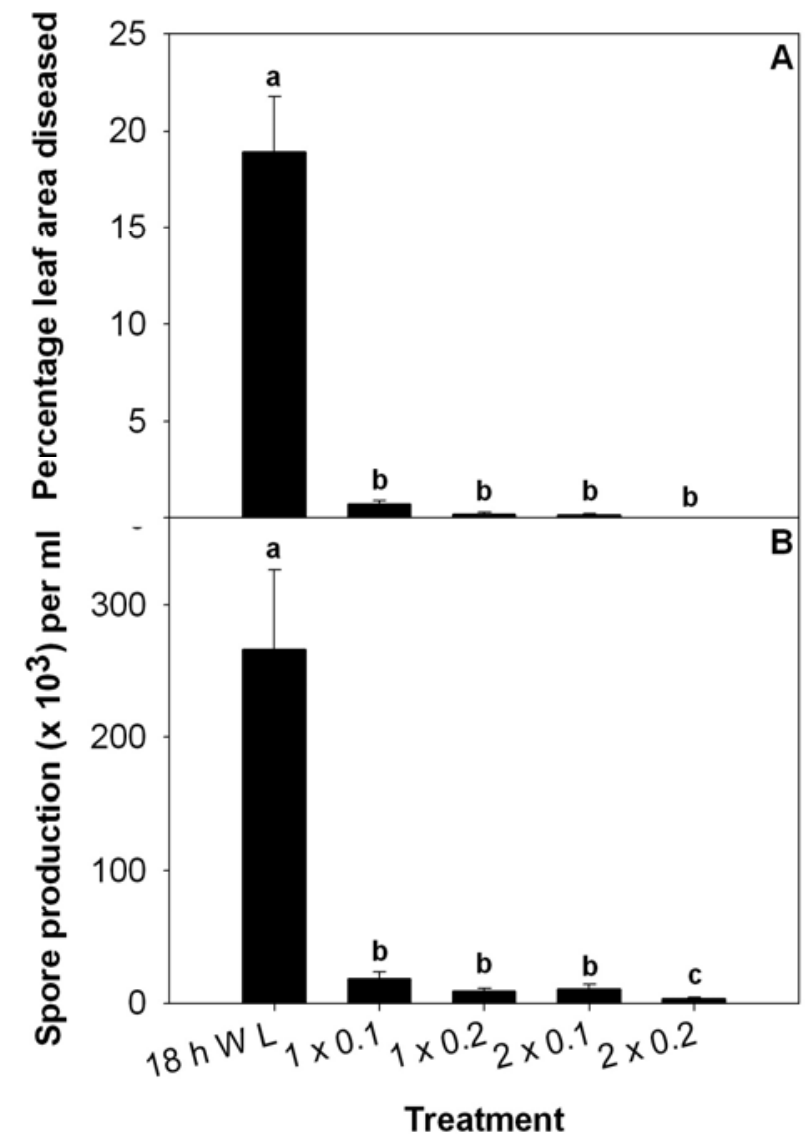

Fig. 5. Effect of daily light cycles of $18 \mathrm{~h}$ of white light (WL) or $18 \mathrm{~h}$ of WL combined with UV-B radiation of either $1 \mathrm{~h}$ at $0.1 \mathrm{~W} \mathrm{~m}^{-2}(1 \times 0.1), 1 \mathrm{~h}$ at $0.2 \mathrm{~W} \mathrm{~m}^{-2}(1 \times 0.2), 2$ $\mathrm{h}$ at $0.1 \mathrm{~W} \mathrm{~m}^{-2}(2 \times 0.1)$, or $2 \mathrm{~h}$ at $0.2 \mathrm{~W} \mathrm{~m}^{-2}(2 \times 0.2)$ on $\mathbf{A}$, disease severity or $\mathbf{B}$, spore formation 9 days after inoculation with Podosphaera pannosa on pot rose (Rosa $\times$ hybrida) 'Toril'. Data for spore production were log transformed $(1+$ number of spores) before analysis, and back-transformed data are presented here. Error bars are standard error of the mean for two repeated experiments, and significant difference between treatments is denoted by different letters $(P=0.05)$.
The maximal photochemical yield of photosystem II $\left(\mathrm{F}_{\mathrm{v}} / \mathrm{F}_{\mathrm{m}}\right)$ after dark adaptation was not significantly affected by any of the lighting treatments (Table 3). Except for the UV-B exposure of $1 \mathrm{~h}$ at $0.1 \mathrm{~W} \mathrm{~m}^{-2}$, the relative content of flavonol increased significantly with the UV-B treatments $(P \leq 0.0001$; Table 3$)$. The relative flavonol content was highest with treatment of $2 \mathrm{~h}$ of UV-B radiation at $0.2 \mathrm{~W} \mathrm{~m}^{-2}$. The relative anthocyanin content was significantly higher in roses grown under UV-B exposure for $1 \mathrm{~h}$ at $0.2 \mathrm{~W} \mathrm{~m}^{-2}$ and $2 \mathrm{~h}$ at $0.1 \mathrm{~W} \mathrm{~m}^{-2}$, compared with the other treatments $(P=$ 0.0001 ; Table 3). The relative anthocyanin content at the highest level of UV-B and exposure time $\left(2 \mathrm{~h}\right.$ with $\left.0.2 \mathrm{~W} \mathrm{~m}^{-2}\right)$ was not different from the non-exposed control. Exposure duration of 15 days gave the highest relative contents of both flavonol and

Table 2. Effect of $18 \mathrm{~h}$ of white light (WL) and $18 \mathrm{~h}$ of WL with different combinations of night-time exposure to UV-B radiation on percent germinated spores and successful infections with Podosphaera pannosa on pot rose (Rosa $\times$ hybrida) 'Toril'w

\begin{tabular}{lcc}
\hline Treatment $^{\mathbf{x}}$ & Germination $^{\mathbf{y}}$ & Infection $^{\mathbf{z}}$ \\
\hline $18 \mathrm{~h}$ of WL & $33.3 \pm 2.6 \mathrm{a}$ & $13.5 \pm 1.8 \mathrm{a}$ \\
$1 \times 0.1$ & $11.3 \pm 1.9 \mathrm{~b}$ & $2.0 \pm 1.1 \mathrm{~b}$ \\
$1 \times 0.2$ & $3.5 \pm 0.9 \mathrm{c}$ & $0.3 \pm 0.2 \mathrm{~b}$ \\
$2 \times 0.1$ & $11.0 \pm 1.5 \mathrm{~b}$ & $1.3 \pm 0.5 \mathrm{~b}$ \\
$2 \times 0.2$ & $5.7 \pm 0.7 \mathrm{bc}$ & $0.2 \pm 0.2 \mathrm{~b}$ \\
\hline
\end{tabular}

${ }^{\mathrm{w}}$ In each leaf, 50 individual conidia were assessed, and four leaves were assessed per treatment in each experimental repeat. Data are the means \pm standard error for two repeated experiments. Different letters in each column indicates significant difference between treatments $(P=0.05)$.

${ }^{x}$ UV-B exposure was either $1 \mathrm{~h}$ at $0.1 \mathrm{~W} \mathrm{~m}^{-2}(1 \times 0.1), 1 \mathrm{~h}$ at $0.2 \mathrm{~W} \mathrm{~m}^{-2}(1$ $\times 0.2), 2 \mathrm{~h}$ at $0.1 \mathrm{~W} \mathrm{~m}^{-2}(2 \times 0.1)$, or $2 \mathrm{~h}$ at $0.2 \mathrm{~W} \mathrm{~m}^{-2}(2 \times 0.2)$.

${ }^{y}$ Conidia were considered germinated when the germ tube length was equal to or longer than the conidial width, recorded 2 days after inoculation.

${ }^{z}$ Conidia were considered to have caused successful infections when hyphae originating from them had branched, recorded 3 days after inoculation.

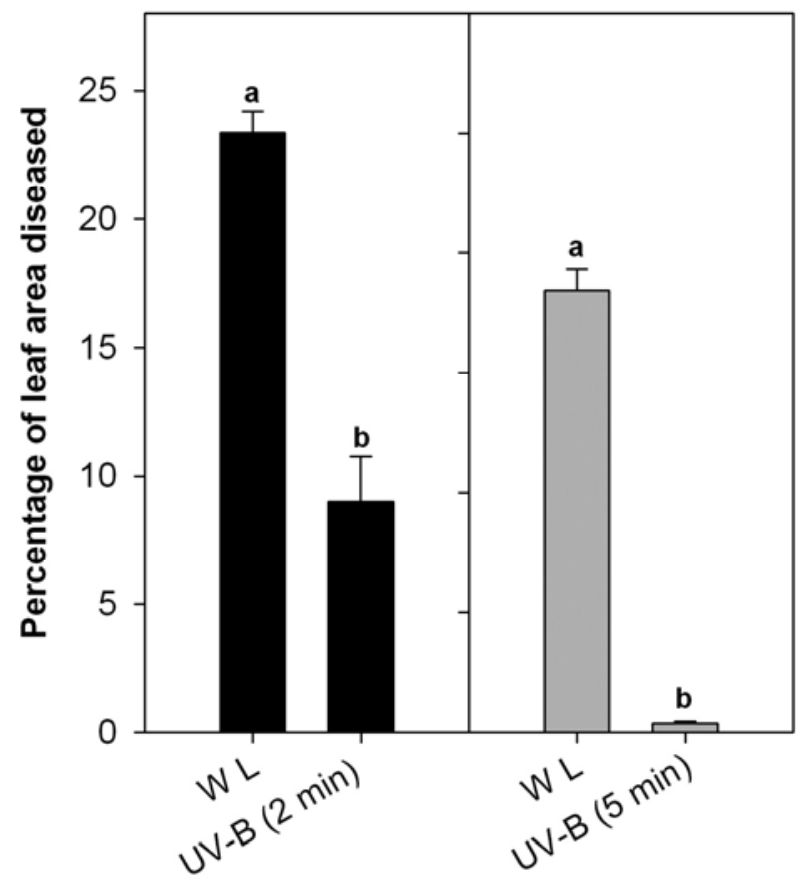

Treatment

Fig. 6. Effect of UV-B on disease severity 9 days after inoculation with Podosphaera pannosa on pot rose (Rosa $\times$ hybrida) 'Toril'. Inoculated plants were exposed to treatments of $18 \mathrm{~h}$ of white light (WL) or $18 \mathrm{~h}$ of WL $+2 \mathrm{~h}$ of darkness + 2 or $5 \mathrm{~min}$ of UV-B at $1.2 \mathrm{~W} \mathrm{~m}^{-2}$. Error bars are standard error of the mean for two repeated experiments, and significant difference between treatments is denoted by different letters $(P=0.05)$. 
anthocyanin, and the differences were significant compared with 5 or 10 days of exposure $(P=0.0001$; data not shown $)$.

Effect of UV-B on plant growth. The height of the roses was significantly reduced under UV-B treatments for $2 \mathrm{~h}$ at $0.1 \mathrm{~W} \mathrm{~m}^{-2}$ $(P=0.025)$ and $2 \mathrm{~h}$ at $0.2 \mathrm{~W} \mathrm{~m}^{-2}(P=0.001)$ compared with $18 \mathrm{~h}$ of white light (Table 4). Also, the mean leaf area after 30 days of exposure was reduced by 36 and $17 \%$ if exposed to $2 \mathrm{~h}$ UV-B at $0.2 \mathrm{~W} \mathrm{~m}^{-2}$ and $1 \mathrm{~h} \mathrm{UV}-\mathrm{B}$ at $0.2 \mathrm{~W} \mathrm{~m}^{-2}$, respectively, compared with the non-UV-B exposed control $(P \leq 0.0001)$. All other UV-B treat-

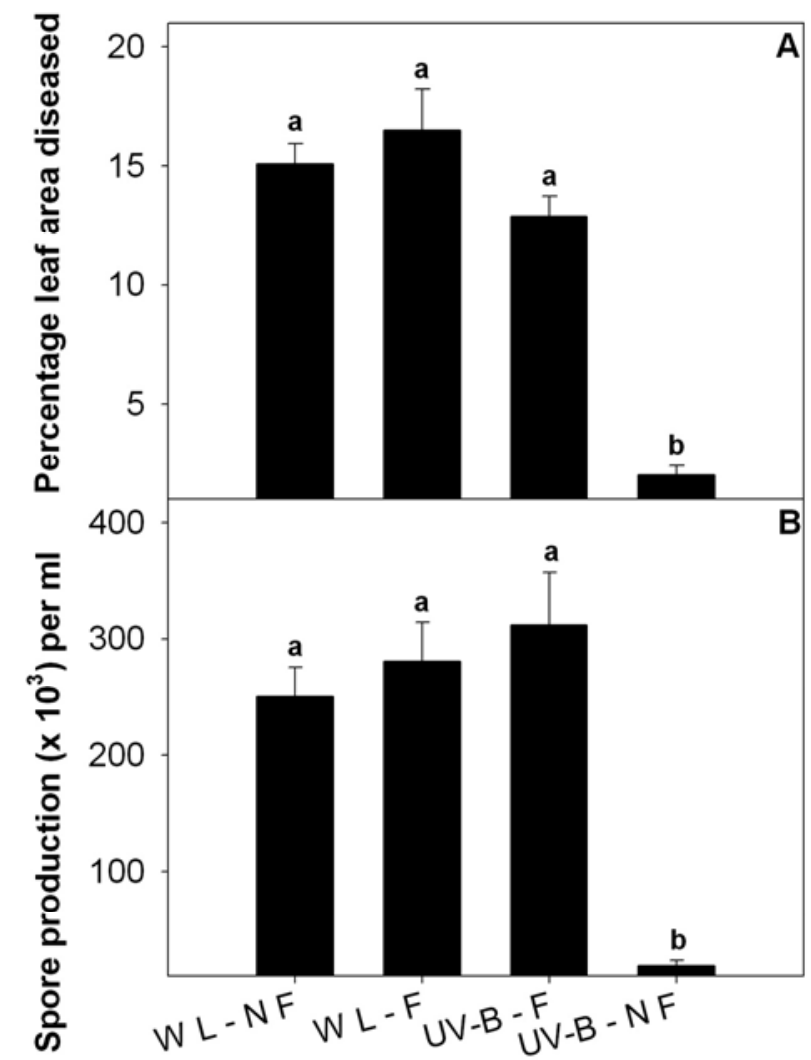

Treatment

Fig. 7. Effect of the different parts of the UV-B spectrum on A, disease severity and B, spore formation 9 days after inoculation with Podosphaera pannosa on pot rose (Rosa $\times$ hybrida) 'Toril'. Inoculated roses were exposed to daily light cycles of either $18 \mathrm{~h}$ of white light (WL) or $18 \mathrm{~h}$ of WL $+2 \mathrm{~h}$ of darkness (D) $+1 \mathrm{~h}$ of UV-B at $0.1 \mathrm{~W}$ $\mathrm{m}^{-2}+3 \mathrm{~h}$ of $\mathrm{D}$, and the light was either filtered $(\mathrm{F})$ to omit wavelengths below 290 $\mathrm{nm}$ or not filtered (NF) with cellulose diacetate. Data for spore production were log transformed before analysis, and back-transformed data are presented here. Error bars are standard error of the mean for two repeated experiments, and significant difference between treatments is denoted by different letters $(P=0.05)$. ments did not significantly affect leaf area compared with unexposed controls (Table 4). The dry weight of the aboveground plant parts was significantly reduced in plants exposed to $2 \mathrm{~h}$ of UV-B at $0.2 \mathrm{~W} \mathrm{~m}^{-2}$ compared with all the other treatments $(P \leq 0.0001$; Table 4). The number of flower buds was not significantly reduced by any of the treatments (Table 4).

\section{Discussion}

All treatments wherein the full spectrum of UV-B radiation was applied after inoculation reduced the severity of powdery mildew in greenhouse-grown roses. The means by which this reduction occurred was manifested at multiple levels: conidial germination, infection efficiency, and sporulation were all reduced. Pathogen sporulation was equivalently reduced with UV-B at 0.1 or $0.2 \mathrm{~W}$ $\mathrm{m}^{-2}$ for 1 or $2 \mathrm{~h}$. Suppression of conidial germination increased as UV-B intensity increased but not as time of exposure increased. Similar finding was reported on conidial germination of Colletotrichum orbiculare (11). In contrast, conidial germination and hyphal growth of E. necator depended on total UV-B dose (intensity $\times$ duration; 36). UV-B exposures lasting $2 \mathrm{~h}$ at $0.2 \mathrm{~W} \mathrm{~m}^{-2}$ had a clear negative effect on plant growth and quality. However, brief daily exposures of pot rose Toril to night interruption UV-B radiation for $1 \mathrm{~h}$ at $0.1 \mathrm{~W} \mathrm{~m}^{-2}$ or $5 \mathrm{~min}$ at $1.2 \mathrm{~W} \mathrm{~m}^{-2}$ were sufficient to substantially suppress disease, with no significant effects on plant growth.

UV radiation is known to suppress or kill a variety of fungi. What distinguishes our work from previous studies $(11,36)$ are the relatively brief exposure times and UV-B intensities employed and, to some extent, the nature of the pathosystem investigated (i.e., with the exception of the haustoria within parasitized epidermal cells, powdery mildews [except tribe Phyllactinieae] are wholly external to the host; 14). Furthermore, with the exception of the cleistothecial wall, powdery mildews are devoid of melanin or other polyphenolic compounds thought to afford protection from UV radiation. Thus, powdery mildews may be unusually amenable to suppression with relatively short exposures to low-intensity UV$\mathrm{B}$ radiation. Conidial germination and mycelial growth of $E$. necator was reduced on detached grapevine leaves exposed to UV-B radiation for $4 \mathrm{~h}$ at $1.3 \mathrm{~W} \mathrm{~m}^{-2}$ or $8 \mathrm{~h}$ at $0.7 \mathrm{~W} \mathrm{~m}^{-2}$ (36). Suppression of conidial germination and appressorium formation in $C$. orbiculare required exposure to UV-B for $2 \mathrm{~h}$ at $2.32 \mathrm{~W} \mathrm{~m}^{-2}$ (11). Although brief daily exposures to UV-B clearly reduced disease severity in our studies, severity eventually increased when UV-B treatments were discontinued and plants were returned to normal light conditions. The effect of UV-B was not persistent, and daily brief exposure to UV-B may be necessary to achieve commercially relevant levels of disease suppression.

UV-B radiation has been thought to induce resistance in some pathosystems $(17,20,23)$. Genes coding for pathogenesis-related (PR) proteins were expressed in strawberry but at a UV-B dose 10 times higher than in our experiments (20). In French bean

Table 3. Effect of treatments with $18 \mathrm{~h}$ of white light (WL) or $18 \mathrm{~h}$ of WL with different combinations of night-time exposure to UV-B radiation on relative concentration of chlorophyll, the chlorophyll fluorescence parameter (variable fluorescence/maximum fluorescence $\left[\mathrm{F}_{\mathrm{v}} / \mathrm{F}_{\mathrm{m}}\right]$ ), flavonol, and anthocyanin in pot rose (Rosa $\times$ hybrida) 'Toril'v

\begin{tabular}{lcccc}
\hline Treatment $^{\mathbf{w}}$ & Chlorophyll $^{\mathbf{x}}$ & $\mathbf{F}_{\mathbf{v}} / \mathbf{F}_{\mathbf{m}} \mathbf{y}^{\mathbf{3}}$ & Flavonol $^{\mathbf{z}}$ & Anthocyanin $^{\mathbf{z}}$ \\
\hline 18 h of WL & $17.80 \pm 1.56 \mathrm{~b}$ & $0.786 \pm 0.0016 \mathrm{a}$ & $0.914 \pm 0.013 \mathrm{c}$ & $1.110 \pm 0.0120 \mathrm{~b}$ \\
$1 \times 0.1$ & $17.98 \pm 1.62 \mathrm{~b}$ & $0.789 \pm 0.0017 \mathrm{a}$ & $0.935 \pm 0.010 \mathrm{c}$ & $1.101 \pm 0.0086 \mathrm{~b}$ \\
$1 \times 0.2$ & $20.94 \pm 1.82 \mathrm{a}$ & $0.787 \pm 0.0019 \mathrm{a}$ & $1.043 \pm 0.016 \mathrm{~b}$ & $1.192 \pm 0.0159 \mathrm{a}$ \\
$2 \times 0.1$ & $20.41 \pm 1.89 \mathrm{a}$ & $0.792 \pm 0.0022 \mathrm{a}$ & $1.179 \pm 0.022 \mathrm{a}$ & $1.214 \pm 0.0132 \mathrm{a}$ \\
$2 \times 0.2$ & $20.23 \pm 1.71 \mathrm{a}$ & $0.791 \pm 0.0023 \mathrm{a}$ & $1.182 \pm 0.021 \mathrm{a}$ & $1.122 \pm 0.0080 \mathrm{~b}$ \\
\hline
\end{tabular}

${ }^{v}$ All data were subject to two-way analyses of variance (light treatment and duration). Values are mean and standard error of two repeated experiments. Chlorophyll and $\mathrm{F}_{\mathrm{v}} / \mathrm{F}_{\mathrm{m}}$ are means of measurements 10, 20, and 30 days, flavonol and anthocyanin are means of 5, 10, 15 and 20 days after start of experiments. Different letters between treatments in a column indicate significant differences at $P=0.05$.

${ }^{w} \mathrm{UV}-\mathrm{B}$ exposure was either $1 \mathrm{~h}$ at $0.1 \mathrm{~W} \mathrm{~m}^{-2}(1 \times 0.1), 1 \mathrm{~h}$ at $0.2 \mathrm{~W} \mathrm{~m}^{-2}(1 \times 0.2), 2 \mathrm{~h}$ at $0.1 \mathrm{~W} \mathrm{~m}^{-2}(2 \times 0.1)$, or $2 \mathrm{~h}$ at $0.2 \mathrm{~W} \mathrm{~m}^{-2}(2 \times 0.2)$.

${ }^{x}$ Recorded with a hand-held chlorophyll content meter (Hansatech Instruments) for the upper two leaves in each plant.

y Recorded with a portable chlorophyll fluorometer (Plant Efficiency Analyser; Hansatech instruments), using excitation light of $1,500 \mu \mathrm{mol} \mathrm{m}{ }^{-2} \mathrm{~s}^{-1}$ after 15 min of dark adaptation for the upper two leaves in each plant.

${ }^{\mathrm{z}}$ Three repeated measurements of each plant canopy by a Multiplex 3 multi-excitation wavelength chlorophyll fluorometer (Force-A). Values are relative to the blue standard provided by the manufacturer. 
(Phaseolus vulgaris), UV-B wavelengths below $295 \mathrm{~nm}$ more efficiently induced the PR protein $\beta$-1,3-glucanase than wavelengths between 295 and $360 \mathrm{~nm}$ (21). However, brief exposure of roses to UV-B daily for 1 week followed by inoculation did not affect Podosphaera pannosa development, indicating that the treatment effect was directly upon the exposed pathogen.

Flavonoids and phenolic compounds have been reported to act as phytoalexins or antifungal compounds $(24,27)$, increasing the plant resistance to fungal diseases $(13,29)$. In our experiments, there were slight increases in flavonoids (flavonol and anthocyanin) but, at the lowest UV-B exposure time and level $(1 \mathrm{~h}$ at $0.1 \mathrm{~W}$ $\mathrm{m}^{-2}$ ), there was no significant increase in these compounds, although these UV-B treatment levels effectively suppressed development of powdery mildew. In the case of $P$. pannosa and, possibly, other biotrophic plant pathogens, our results indicate that some caution is advisable in attributing effects of UV-B to induced resistance, where pathogen suppression may be due to the general phytotoxic effects of certain doses of UV-B upon the host.

Our finding that maximal efficacy of UV-B against $P$. pannosa was dependent on wavelengths between 280 and $290 \mathrm{~nm}$ was similar to findings reported for $C$. orbiculare (11). Contrary to our finding of no disease suppression with UV-B at wavelengths above $290 \mathrm{~nm}$, conidial germination and appressorium formation by $C$. orbiculare were reduced in full-spectrum sunlight in wavelengths extending from 300 to 3,000 nm compared with shade control (11). Likewise, E. necator on grapevine leaves was suppressed by solar radiation (300 to $3,000 \mathrm{~nm}$ ) compared with shaded controls (36). However, without isolating specific wavebands, the relative contribution of any particular waveband to disease suppression cannot be precisely ascertained. In plants, weighting functions have been developed for a range of UV wavelengths, indicating their relative biological impact on various plant processes (9). The most commonly used formulation indicates no effect of wavelengths greater than $313 \mathrm{~nm}$ on various plant processes (16). We are not aware of any corresponding weighting system of effects of various wavelengths of light in fungi. Our results and those of other studies on fungi (11) indicate considerable inefficiency of UV-B at wavelengths above $290 \mathrm{~nm}$ compared with the 313-nm threshold suggested for plants (16), and this shows the necessity for determination of spectral weighting functions specific for various fungal responses.

Roses grown at the highest UV-B levels developed smaller leaves but the number of leaves was not affected (data not shown). In wheat plants, elevated UV-B radiation reduced leaf area by reducing the rate of cell division (19). Leaf expansion in greenhousegrown Gunnera magellanica (12) and total dry weight of pea (15) also decreased as UV-B dose was increased. Reduced dry weight in plants exposed to supplemental UV-B has been attributed to reduced activity of photosystem II photochemistry $(4,8)$. We found no significant change in chlorophyll fluorescence $\left(\mathrm{F}_{\mathrm{v}} / \mathrm{F}_{\mathrm{m}}\right)$ in UV-Bexposed plants, indicating that inhibition of photosystem II was not a reason for reduced dry weight in roses exposed to UV-B. De- pending on the particular crop species investigated, UV-B treatments have either increased (30), decreased $(2,37)$, or had no effect upon total chlorophyll content of leaves (22). We found that total chlorophyll content increased in plants exposed to higher UV-B doses, and this may be due to increased biosynthesis of chlorophyll under supplemental UV-B.

We have demonstrated that we can suppress powdery mildew on roses by exposing plants to UV-B for $5 \mathrm{~min}$ at $1.2 \mathrm{~W} \mathrm{~m}^{-2}$ during darkness without significant phytotoxic host effects at either the gross morphological or physiological level. We have previously shown the potential for manipulating day length and light quality to reduce powdery mildew in roses $(32,33)$. Brief exposure to UVB offers yet another nonchemical tool in the management of this disease. Use of reflective ground cover may improve the efficiency of UV-B $(25,26)$, and provide better exposure of abaxial leaf surfaces to treatments. Currently, we are investigating use of UV-B and supplemental lighting from low-energy LEDs for management of powdery mildews in other greenhouse crops (unpublished data).

\section{Acknowledgments}

This research was financed by the Norwegian Research Council and The Norwegian Growers' Association (NGF). We would like to express our sincere thanks to technicians at Centre for Plant Research (SKP) and Norwegian Institute for Agricultural and Environmental Research (Bioforsk).

\section{Literature Cited}

1. Austin, C. N., Meyers, J., Grove, G. G., and Wilcox, W. F. 2011 Quantification of powdery mildew severity as a function of canopy variability and associated impacts on sunlight penetration and spray coverage within the fruit zone. Am. J. Enol. Vitic. 62:23-31.

2. Balakrishnan, V., Ravindran, K. C., Venkatesan, K., and Karuppusamy, S 2005. Effect of UV-B supplemental radiation on growth and biochemical characteristics in Crotalaria juncea L. seedlings. Electron. J. Environ. Agric. Food Chem. 4:1125-1131.

3. Blaustein, A. R., and Sengsavanh, N. 2000. Ultraviolet radiation. Pages 723-732 in: Encyclopedia of Biodiversity. S. A. Levin, ed. Academic Press, Massachusetts.

4. Caldwell, M. M., Ballare, C. L., Bornman, J. F., Flint, S. D., Bjorn, L. O., Teramura, A. H., Kulandaivelu, G., and Tevini, M. 2003. Terrestrial ecosystems, increased solar ultraviolet radiation and interactions with other climatic change factors. Photochem. Photobiol. S. 2:29-38.

5. Cerovic, Z. G., Moise, N., Agati, G., Latouche, G., BenGhozlen, N., and Meyer, S. 2008. New portable optical sensors for the assessment of winegrape phenolic maturity based on berry fluorescence. J. Food Compos. Anal. 21:650-654.

6. Crutzen, P. J. 1992. Ultraviolet on the increase. Nature 356:104-105.

7. Daughtrey, M. L., and Benson, D. M. 2005. Principles of plant health management for ornamental plants. Annu. Rev. Phytopathol. 43:141-169.

8. Fiscus, E. L., and Booker, F. L. 1995. Is increased UV-B a threat to crop photosynthesis and productivity? Photosynth. Res. 43:81-92.

9. Flint, S. D., and Caldwell, M. M. 2003. A biological spectral weighting function for ozone depletion research with higher plants. Physiol. Plant. 117:137-144.

10. Gadoury, D. M., Pearson, R. C., Seem, R. C., Henick-Kling, T., Creasy, L. L., and Michaloski, A. 1991. Control of fungal diseases of grapevine by short-wave ultraviolet light (Abstr.) Phytopathology 82:243.

11. Ghajar, F., Holford, P., Cother, E., and Beattie, A. 2006. Effects of ultraviolet radiation, simulated or as natural sunlight, on conidium germination and

Table 4. Effect of treatments with $18 \mathrm{~h}$ of white light (WL) or $18 \mathrm{~h}$ of WL with different combinations of night-time exposure to UV-B radiation on growth and number of flower buds in pot rose $($ Rosa $\times$ hybrida) 'Toril'u

\begin{tabular}{lccc}
\hline Treatment $^{\mathbf{v}}$ & Plant height $(\mathbf{c m})^{\mathbf{w}}$ & ${\text { Leaf area }\left(\mathbf{c m}^{\mathbf{2}}\right)^{\mathbf{x}}}$ & ${\text { Total dry weight }(\mathbf{g})^{\mathbf{y}}}^{\text {Flower buds }^{\mathbf{z}}}$ \\
\hline $18 \mathrm{~h} \mathrm{WL}$ & $15.9 \pm 1.2 \mathrm{a}$ & $739.6 \pm 78.8 \mathrm{a}$ & $4.9 \pm 0.75 \mathrm{a}$ \\
$1 \times 0.1$ & $15.1 \pm 1.1 \mathrm{ab}$ & $689.1 \pm 75.8 \mathrm{ab}$ & $4.7 \pm 0.74 \mathrm{a}$ \\
$1 \times 0.2$ & $15.5 \pm 1.0 \mathrm{ab}$ & $625.3 \pm 64.3 \mathrm{~b}$ & $4.6 \pm 0.67 \mathrm{a}$ \\
$2 \times 0.1$ & $14.7 \pm 1.1 \mathrm{~b}$ & $650.7 \pm 66.6 \mathrm{ab}$ & $4.4 \pm 0.66 \mathrm{a}$ \\
$2 \times 0.2$ & $14.4 \pm 1.0 \mathrm{~b}$ & $482.0 \pm 54.9 \mathrm{c}$ & $3.5 \pm 0.54 \mathrm{~b}$ \\
\hline
\end{tabular}

u All data were subject to two-way analysis (light treatment and duration). Values are mean and standard error of two repeated experiments. Plant height is mean of measurements 5, 10, 15, and 20 days after start of experiments; leaf area and total dry weight are means of 10 , 20 , and 30 days after start of experiments. Different letters between treatments in a column indicate significant differences at $P=0.05$.

${ }^{\mathrm{v}} \mathrm{UV}-\mathrm{B}$ exposure was either $1 \mathrm{~h}$ at $0.1 \mathrm{~W} \mathrm{~m}^{-2}(1 \times 0.1), 1 \mathrm{~h}$ at $0.2 \mathrm{~W} \mathrm{~m}^{-2}(1 \times 0.2), 2 \mathrm{~h}$ at $0.1 \mathrm{~W} \mathrm{~m}^{-2}(2 \times 0.1)$, or $2 \mathrm{~h}^{2}$ at $0.2 \mathrm{~W} \mathrm{~m}^{-2}(2 \times 0.2)$.

${ }^{\mathrm{w}}$ Defined as the distance from the base of the shoot to the node of the fully unfolded uppermost leaf.

${ }^{x}$ Leaf area of the unfolded leaves was measured by an LI-3100 area meter (Li-Cor, Inc.).

y Above-soil plant parts kept at $70^{\circ} \mathrm{C}$ in dryer for 10 days before measurements.

z Number of visible flower buds were counted 20 days after exposure to treatments. 
appressorium formation by fungi with potential as mycoherbistats. Biocontrol Sci. Technol. 16:451-469.

12. Giordano, C. V., Galatro, A., Puntarulo, S., and Ballare, C. L. 2004. The inhibitory effects of UV-B radiation (280-315 nm) on Gunnera magellanica growth correlate with increased DNA damage but not with oxidative damage to lipids. Plant Cell Environ. 27:1415-1423.

13. Glabgen, W. E., Rose, A., Madlung, J., Koch, W., Gleitz, J., and Seitz, H. U. 1998. Regulation of enzymes involved in anthocyanin biosynthesis in carrot cell cultures in response to treatment with ultraviolet light and fungal elicitors. Planta 204:490-498.

14. Glawe, D. A. 2008. The powdery mildews: a review of the world's most familiar (yet poorly known) plant pathogens. Annu. Rev. Phytopathol. 46:27-51.

15. Gonzalez, R., Mepsted, R., Wellburn, A. R., and Paul, N. D. 1998. Nonphotosynthetic mechanisms of growth reduction in pea (Pisum sativum L.) exposed to UV-B radiation. Plant Cell Environ. 21:23-32.

16. Green, A. E. S., Sawada, T., and Shettle, E. P. 1974. The middle ultraviolet reaching the ground. Photochem. Photobiol. 19:251-259.

17. Green, R., and Fluhr, R. 1995. UV-B induced PR-1 accumulation is mediated by active oxygen species. Plant Cell 7:203-212.

18. Hockberger, P. E. 2002. A history of ultraviolet photobiology for humans, animals and microorganisms. Photochem. Photobiol. 76:561-579.

19. Hopkins, L., Bond, M. A., and Tobin, A. K. 2002. Ultraviolet-B radiation reduces the rates of cell division and elongation in the primary leaf of wheat (Triticum aestivum L. cv Maris Huntsman). Plant Cell Environ. 25:617-624.

20. Kanto, T., Matsuura, K., Yamada, M., Usami, T., and Amemiya, Y. 2009. UV-B radiation for control of strawberry powdery mildew. Acta Hortic. 842:359-362.

21. Kucera, B., Leubner-Metzger, G., and Wellmann, E. 2003. Distinct ultraviolet-signaling pathways in bean leaves. DNA damage is associated with $\beta$ 1,3-glucanase gene induction, but not with flavanoid formation. Plant Physiol. 133:1445-1452.

22. Kumari, R., Singh, S., and Agrawal, S. B. 2009. Effects of supplemental ultraviolet-B radiation on growth and physiology of Acorus calamus L. (Seet Flag). Acta Biol. Cracov. Ser. Bot. 51:19-27.

23. Kunz, B. A., Dando, P. K., Grice, D. M., Mohr, P. G., Schenk, P. M., and Cahill, D. M. 2008. UV-induced DNA damage promotes resistance to the biotrophic pathogen Hyaloperonospora parasitica in Arabidopsis. Plant Physiol. 148:1021-1031.

24. Lo, C., Coolbaugh, R. C., and Nicholson, R. L. 2002. Molecular characterization and in silico expression analysis of a chalcone synthase gene family in Sorghum bicolor. Physiol. Mol. Plant Pathol. 61:179-188.

25. Meinhold, T., Damerow, L., and Blanke, M. M. 2011. Reflective materials under hailnet improve orchard light utilisation, fruit quality and particularly fruit colouration. Sci. Hortic. 127:447-451.

26. Meinhold, T., Richters, J. P., Damerow, L., and Blanke, M. M. 2010. Optical properties of reflection ground covers with potential for enhancing fruit colouration. Biosyst. Eng. 107:155-160.

27. Modolo, L. V., Cunha, F. Q., Braga, M. R., and Salgado, I. 2002. Nitric oxide synthase-mediated phytoalexin accumulation in soybean cotyledons in response to the Diaporthe phaseolorum $\mathrm{f}$. sp. meridionalis elicitor. Plant Physiol. 130:1288-1297.

28. Newsham, K. K., Oxborough, K., White, R., Greenslade, P. D., and McLeod, A. R. 2000. UV-B radiation constrains the photosynthesis of Quer cus robur through impacts on the abundance of Microsphaera alphitoides. For. Pathol. 30:265-275.

29. Picman, A. K., Schneider, E. F., and Picman, J. 1995. Effects of flavonoids on mycelial growth of Verticillium albo-atrum. Biochem. Syst. Ecol. 23:683-693.

30. Smith, J. L., Burritt, D. J., and Bannister, P. 2000. Shoot dry weight, chlorophyll and UV-B-absorbing compounds as indicators of a plant's sensitivity to UV-B radiation. Ann. Bot. 86:1057-1063.

31. Suthaparan, A., Stensvand, A., Solhaug, K. A., Mortensen, L. M., Eriksen, A. S., Torre, S., Gadoury, D. M., and Gislerod, H. R. 2011. Bruk av UV-B stråling til bekjempelse av mjøldogg i veksthusroser (in Norwegian). Bioforsk Fokus 6(2):91.

32. Suthaparan, A., Stensvand, A., Torre, S., Herrero, M., L., Pettersen, R. I. Gadoury, D. M., and Gislerød, H. R. 2010. Continuous lighting reduces conidial production and germinability in the rose powdery mildew pathosystem. Plant Dis. 94:339-344.

33. Suthaparan, A., Torre, S., Stensvand, A., Herrero, M. L., Pettersen, R. I., Gadoury, D. M., and Gislerød, H. R. 2010. Specific light emitting diodes can suppress sporulation of Podosphaera pannosa on greenhouse roses. Plant Dis. 94:1105-1110.

34. Sutherland, J. C. 2002. Biological effects of polychromatic light. Photochem. Photobiol. 76:164-170.

35. Wang, H., Jiang, Y. P., Yu, H. J., Xia, X. J., Shi, K., Zhou, Y. H., and Yu, J. Q. 2010. Light quality affects incidence of powdery mildew, expression of defence related genes and associated metabolism in cucumber plants. Eur. J. Plant Pathol. 127:125-135.

36. Willocquet, L., Colombet, D., Rougier, M., Fargues, J., and Clerjeau, M 1996. Effects of radiation, especially ultraviolet B, on conidial germination and mycelial growth of grape powdery mildew. Eur. J. Plant Pathol. 102:441-449.

37. Zhao, D., Reddy, K. R., Kakani, V. G., Read, J., and Sullivan, J. H. 2003 Growth and physiological responses of cotton (Gossypium hirsutum L.) to elevated carbon dioxide and ultraviolet-B radiation under controlled environment conditions. Plant Cell Environ. 26:771-782. 